\title{
Effects of Humic Acid and Natural Sunlight Irradiation on the Behaviour of Zinc Oxide Nanoparticles in the Aqueous Environment
}

\author{
Valach Andrian Velintine ${ }^{1}$, Boon Siong Wee ${ }^{1, * \mathbb{C}}$, Eric Kwabena Droepenu ${ }^{1}{ }^{\mathbb{D}}$, Suk Fun Chin $^{1}{ }^{10}$, Kuan \\ Ying Kok ${ }^{2}$ (D) \\ 1 Chemistry Programme, Faculty of Resource Science and Technology, Universiti Malaysia Sarawak, Kota Samarahan, \\ 94300, Sarawak, MALAYSIA; veevelintine@gmail.com (V.A.V.); swboon@unimas.my $\quad$ (B.S.W.); \\ kobladodzie01@yahoo.com (E.K.D.); sfchin@unimas.my (S.F.C.); \\ 2 Malaysian Nuclear Agency, Bangi, Kajang, 43000 Selangor, MALAYSIA; kyk1000@ nuclearmalaysia.gov.my (K.Y.K.); \\ * Correspondence: swboon@unimas.my;
}

Scopus Author ID 57194506096

Received: 12.11.2020; Revised: 6.12.2020; Accepted: 8.12.2020; Published: 10.12.2020

\begin{abstract}
The unique properties of $\mathrm{ZnO}$ nanoparticles have attracted scientists' interest to produce on a large-scale. Household items, cosmetics, consumer products, and electric sensors are some products that utilize these $\mathrm{ZnO}$ nanomaterials. Eventually, $\mathrm{ZnO}$ nanoparticles will be released into the environment in various ways. Once released, $\mathrm{ZnO}$ nanoparticles would dissociate into $\mathrm{Zn}^{2+}$ ions, which are toxic to aquatic organisms. The presence of humic acid and exposure to sunlight could affect the dissolution of $\mathrm{ZnO}$ nanoparticles. Two sizes of commercial $\mathrm{ZnO}$ nanoparticles $(<50 \mathrm{~nm}$ and $<100 \mathrm{~nm})$ were chosen to study the influence of humic acid and sunlight on the dissolution. In the presence of humic acid, the dissolution of both sizes is higher, with $67 \%$ and $39 \% \mathrm{Zn}^{2+}$ dissolved for $<50 \mathrm{~nm}$ and $<100 \mathrm{~nm}$, respectively. The concentration of $\mathrm{Zn}^{2+}$ ions seems to be consistent or stable when exposed to sunlight. However, the humic acid enhanced the release of $\mathrm{Zn}^{2+}$ ions. Langmuir isotherm model best fitted for the humic acid's sorption onto the $\mathrm{ZnO}$ nanoparticles with the process been favorable.
\end{abstract}

Keywords: $\mathrm{ZnO}$ nanoparticles; humic acid; sunlight; dissolution; aggregation.

(C) 2020 by the authors. This article is an open-access article distributed under the terms and conditions of the Creative Commons Attribution (CC BY) license (https://creativecommons.org/licenses/by/4.0/).

\section{Introduction}

Applications of nanotechnology in daily usage are already well known [1-6]. To date, nanomaterials' production has become more rapid and on a large scale by years, which consequently increased the amount released to the environment [7-10]. For instance, nanoscale materials' production is expected to exceed $\$ 125$ billion by 2024 [11]. These nanoscale metal oxides exhibit unique physical and chemical properties essential for their applications [12-14]. For example, zinc oxide and titanium dioxide were used in cosmetic and sunscreen products due to their ability to absorb UV light [15-16] and antibacterial activity [17-19]. $\mathrm{ZnO}$ and $\mathrm{TiO}_{2}$ nanoparticles were also widely used as catalysts in water treatment [20], removing pollutants such as dye and humic acid [21-22].

Climate change and hydrological processes could affect the biodegradable activity of dead plants, determining the concentration of organic matter released into the aquatic ecosystem. According to [23], natural organic matters are present in almost all aquatics ecosystems. The concentration is ranging from $0.1-10.0 \mathrm{ppm}$ depending on biogeochemical conditions and climate. Natural organic matter consists of fractions of humic substances such 
as high molecular weight organic molecules (humic acid), soluble in water at $\mathrm{pH}>2$; humin, insoluble in all $\mathrm{pH}$, and fulvic acid, soluble in all $\mathrm{pH}$ [24-25]. However, these organic molecules contain a high abundance of functional groups such as phenolic, carboxylic, hydroxyl, amine, and quinine groups [26], which bind to metal oxide surfaces in water to enhance their mobility. Similarly, the presence of humic acid (HA) can react with chlorine in the water to produce byproducts such as trihalomethane, a carcinogenic substance [27]. In aqueous suspension, any metal oxide nanoparticles have surface sites that are protonated or deprotonated, depending on the $\mathrm{pH}$ value. According to [7,28-29], the adsorption of natural organic matter affecting the surface speciation and net charge of the particles influences their stability, determining their fate, transport, behavior, and bioavailability. Functional groups' presence in the HA structure gave a strong affinity for metal cations, leading to complexation with metal cations [26].

$\mathrm{ZnO}$ nanoparticles are preferred to $\mathrm{TiO}_{2}$ because both have similar catalytic properties of a semiconductor. However, $\mathrm{ZnO}$ exhibits higher electron mobility and a longer photogenerated electron lifetime than $\mathrm{TiO}_{2}$ in the degradation of dyes [30]. $\mathrm{ZnO}$ nanoparticles can also undergo excitation at room temperature under low excitation energy and absorb a larger fraction of the solar spectrum than $\mathrm{TiO}_{2}$ [31]. Also, in large scale operations, $\mathrm{ZnO}$ nanoparticles are low cost, non-toxic, and biocompatible [32]. According to [33], most semiconductors release metal ions during photocatalysis, which poses secondary pollution as well as their interaction with other pollutants. Even though sunlight enhances the photocatalytic properties, it is a concern whether ZnO's properties in the presence of sunlight might enhance the ecological toxicity by releasing more zinc ions under natural environmental conditions [34]. There are fewer reports on the effects of natural sunlight and HA on $\mathrm{ZnO}$ nanoparticles' behavior in an aqueous environment [35-39]. Therefore, this study aimed to investigate the influence of $\mathrm{HA}$ and natural sunlight on $\mathrm{ZnO}$ nanoparticles' behavior in the aquatic environment.

\section{Materials and Methods}

\subsection{Chemicals.}

In this study, zinc oxide $(\mathrm{ZnO})$ nanoparticles of different sizes $(<50 \mathrm{~nm}$ and $<100 \mathrm{~nm})$ were obtained from Sigma-Aldrich. On the other hand, HA used in this experiment was purchased from Sigma-Aldrich, Switzerland. Sodium hydroxide $(\mathrm{NaOH}$; Amresco, Ohio) and nitric acid $\left(\mathrm{HNO}_{3}\right.$; Fisher Chemicals) of concentration $1.0 \mathrm{M}$ were used to adjust sample solutions' $\mathrm{pH}$. Changes in $\mathrm{pH}$ were measured using Martini Instruments (Model Mi 150) $\mathrm{pH}$ meter. Deionized water was used to prepare solutions, and analytical reagent grade chemicals are used without purification.

\subsection{ZnO nanoparticles size distribution.}

The particle size distribution of $\mathrm{ZnO}$ nanoparticle samples was analyzed using Transmission Electron Microscopy (TEM) (JEOL model JEM - 1230) using the modified preparation procedure based on previous studies [40]. Briefly, the $\mathrm{ZnO}$ nanoparticles stock solution was sonicated for 30 minutes to ensure better dispersion among aggregated particles. About $15 \mu \mathrm{L}$ sample solutions were dropped onto coated copper grids and left to dry overnight before viewed under TEM. 


\subsection{Humic acid (HA) preparation.}

Preparation of HA adopted the method reported by [41], with some modifications. A stock solution of humic acid (100 mg/L) was prepared by dissolving a calculated amount in an alkaline solution ( $\mathrm{pH}$ 9) to enable efficient dissolution [42]. From the stock, $10 \mathrm{mg} / \mathrm{L}$ solutions were prepared, and the $\mathrm{pH}$ was adjusted using $\mathrm{HCl}$ and $\mathrm{NaOH}$ solutions. The content was stirred on an electric hotplate magnetic stirrer (Fisherbrand) for 24 hours. Diluted solutions of the HA of different concentrations were prepared and analyzed using UV/ Visible spectrophotometer (UV-1800 SHIMADZU) at a wavelength of $254 \mathrm{~nm}$ [43]. A calibration curve was determined using standardized HA solutions as reported by [44] with a slight modification in the procedure. All stock solution was kept in the fridge and out of light source when not in use.

\subsection{Adsorption study.}

To understand HA's adsorption behaviors on the surface of $\mathrm{ZnO}$ nanoparticles, $<100$ $\mathrm{nm} \mathrm{ZnO}$ was chosen instead of the $<50 \mathrm{~nm} \mathrm{ZnO}$ samples to avoid total dissolution at lower pH. $5 \mathrm{mg}$ of $\mathrm{ZnO}$ powder was added to $5 \mathrm{mg} / \mathrm{L}$ of HA solution of different $\mathrm{pH}(1,3,5,7,9$, 11) and stirred at $150 \mathrm{rpm}$ for 24 hours. After the 24-hour equilibrium, each suspension was filtered using $0.45 \mu \mathrm{m}$ filter paper to remove bigger particulates. The filtrates were analyzed using UV/ Visible spectrophotometer and Atomic Absorption Spectrometer (AAS) for residual concentrations. The amount adsorbed, $\mathrm{Q}(\mathrm{mg} / \mathrm{kg})$, was calculated using the formula reported by [45]:

$\mathrm{Q}=\frac{\left(\mathrm{C}_{0}-\mathrm{C}_{\mathrm{t}}\right) \mathrm{V}}{\mathrm{w}}$

where;

$\mathrm{C}_{0}$ and $\mathrm{C}_{\mathrm{t}}(\mathrm{mg} / \mathrm{L})$ is the liquid-phase concentrations of HA at initial and any given time, respectively. $\mathrm{V}(\mathrm{L})$ is the solution's volume, and $\mathrm{w}(\mathrm{kg})$ is the mass of $\mathrm{ZnO}$ nanoparticles. The adsorption equilibrium data obtained from the study were analyzed using Langmuir and Freundlich's isotherm models reported by [46] in equations 2 and 4.

$\frac{C_{e}}{q_{e}}=\left[\frac{1}{Q_{o} K}\right]+\frac{C_{e}}{Q_{o}}$

where,

$\mathrm{C}_{\mathrm{e}}$ - equilibrium concentration, mg/g, $\mathrm{q}_{\mathrm{e}}$ - amount absorbed at equilibrium, mg/g, $\mathrm{Q}_{\mathrm{o}}$, and $\mathrm{K}$ Langmuir constants relating to adsorption capacity and energy of adsorption, which was determined from the slope and intercept of the linear plot of $\mathrm{C}_{\mathrm{e}} / \mathrm{q}_{\mathrm{e}} \mathrm{Vs} . \mathrm{C}_{\mathrm{e}}$.

The essential features of a Langmuir isotherm can be expressed in terms of a dimensionless constant separation factor or equilibrium parameter, $\mathrm{R}_{\mathrm{L}}$, that is used to predict if an adsorption system is "favorable" or "unfavorable". The separation factor, $\mathrm{R}_{\mathrm{L}}$ is defined by [47] and represented with the Equation:

$R_{L}=\frac{1}{1+K C_{o}}$

where,

$\mathrm{C}_{\mathrm{o}}$ - sorbate concentration, $\mathrm{mg} / \mathrm{l}, \mathrm{K}$ - Langmuir adsorption equilibrium constant, $\mathrm{L} / \mathrm{g}$. The isotherm is unfavorable when $R_{L}>1$, the isotherm is linear when $R_{L}=1$, the isotherm is favorable when $0<R_{L}<1$, and the isotherm is irreversible when $R_{L}=0$ [48].

$\log q_{e}=\log K_{f}+\frac{1}{n} \log C_{e}$

where, 
$\mathrm{q}_{\mathrm{e}}$ - amount adsorbed at equilibrium, $\mathrm{mg} / \mathrm{g}, \mathrm{C}_{\mathrm{e}}$ - equilibrium concentration, $\mathrm{mg} / \mathrm{l}, \mathrm{K}_{\mathrm{f}}$, and $\mathrm{n}$ Freundlich model constants. These constants can be obtained from the slope and intercept of the plot of $\log \mathrm{q}_{\mathrm{e}}$ against $\log \mathrm{C}_{\mathrm{e}}$.

\subsection{Sunlight irradiation experiments.}

The $0.2 \mathrm{~g} / \mathrm{l} \mathrm{ZnO}$ nanoparticles stock solution was prepared by dissolving $\mathrm{ZnO}$ nanoparticles powder in deionized water. The solution was sonicated for 30 minutes to get a better dispersion of particles.

To study the dissolution of $\mathrm{ZnO}$ nanoparticles influenced by sunlight in the presence and absence of humic acid, $0.2 \mathrm{~g} / \mathrm{L}$ stock solution of $\mathrm{ZnO}$ was prepared according to the method reported by [35,49]. A $50 \mathrm{ml}$ volume of each of the $\mathrm{ZnO}$ stock solution and $50 \mathrm{ml}$ of $100 \mathrm{mg} / \mathrm{L}$ HA solutions were sonicated for 10 minutes using Ney ULTRAsonik ( $20 \mathrm{KHz} ; 200 \mathrm{~W} / \mathrm{L}$ ) before adjusting the solution $\mathrm{pH}$ to the desired value. Samples were prepared by using a range of solution conditions: $\mathrm{pH} 1-9$; ionic strength (I) $0-5 \mathrm{mM}$. A concentration of $1.0 \mathrm{M} \mathrm{NaCl}$ was used to adjust the ionic strength of the solutions. The $\mathrm{pH}$ value was measured using Martini Instruments (Model Mi 150) $\mathrm{pH}$ meter. Sunlight irradiation experiment was done from 9 am to $5 \mathrm{pm}$ for two consecutive days. The ambient temperature was $28^{\circ} \mathrm{C} \pm 3{ }^{\circ} \mathrm{C}$ during the experiment. Sunlight intensity was measured using Easy View 30 light Meter (in Lux unit). Dissolution measurement was obtained for every two-hour intervals during two days of exposure. Sunlight intensity was measured every hour of exposure with an average of 0.012 Watt $\mathrm{cm}^{-2}$ after conversion from Lux unit to Watt $\mathrm{cm}^{-2}$ (at $555 \mathrm{~nm}$ ). Total dissolved $\mathrm{Zn}^{2+}$ ion in samples was analyzed using Perkin Elmer Optima 8000 inductively coupled plasma optical emission spectrometer (ICP - OES). At night, the exposed samples were kept in the dark cabinet away from light to prevent degradation. Control experiments were also prepared with the same methods as described above. Instead of exposure to light, the samples were stored in a dark cabinet.

\section{Results and Discussion}

\subsection{Particle size distribution.}

The average diameter determined for the two $\mathrm{ZnO}$ nanoparticles samples $(<50 \mathrm{~nm}$ and $<100 \mathrm{~nm}$ ) from the TEM analysis were $45 \pm 24 \mathrm{~nm}$ and $85 \pm 36 \mathrm{~nm}$ respectively. The particle size distribution is illustrated in Figure 1. The results confirmed that the $<100 \mathrm{~nm} \mathrm{ZnO}$ nanoparticles were more dispersed compared to the $<50 \mathrm{~nm} \mathrm{ZnO}$ nanoparticles. Inlet Figures show the TEM images that were used to calculate the particle size distribution.

On the other hand, the interaction of the $\mathrm{ZnO}$ nanoparticles to HA showed the HA's complexation ability as this was analyzed using TEM shown in Figure 2. According to [26], the presence of functional groups such as carboxyl, hydroxyl, and phenol enables HA to form strong complexations with heavy metal ions in aqueous solutions. The figures also reveal that HA caused the smaller sized $\mathrm{ZnO}$ nanoparticles $(<50 \mathrm{~nm})$ to aggregate more to form bigger clusters [50]. In contrast, the larger sized $\mathrm{ZnO}$ nanoparticles $(<100 \mathrm{~nm})$ did not show greater cluster but rather showed less clustered aggregates in the presence of HA. 


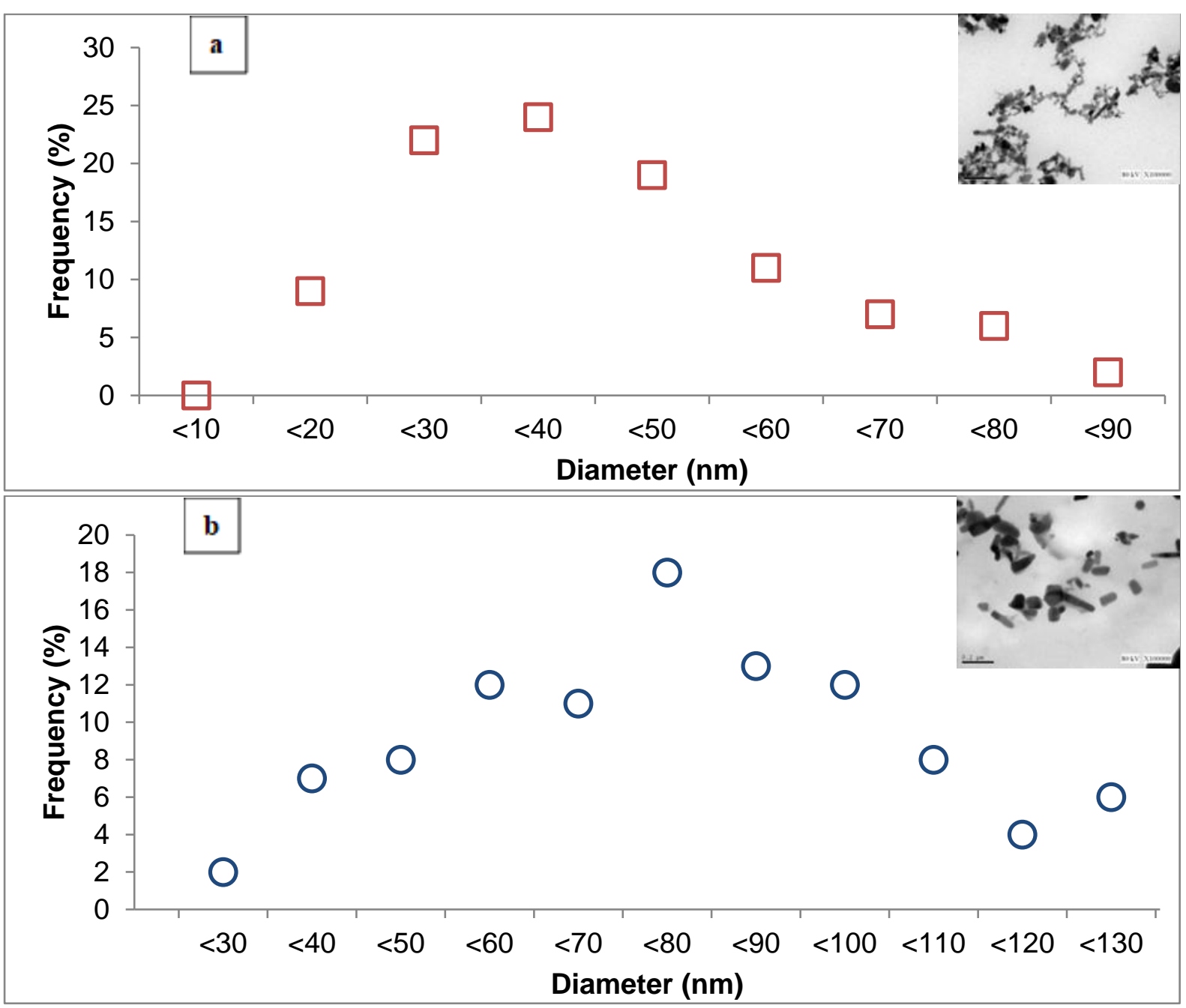

Figure 1. Particle size distribution (TEM) for (a) $<50 \mathrm{~nm} \mathrm{ZnO} \mathrm{(mean} 45 \pm 24 \mathrm{~nm}, \mathrm{n}=247$ ); (b) < 100 $\mathrm{nm} \mathrm{ZnO}$ (mean $85 \pm 36 \mathrm{~nm}, \mathrm{n}=190$ ) displayed as percentage of total count. Inlet is the TEM images of presonicated $\mathrm{ZnO}$ nanoparticles.

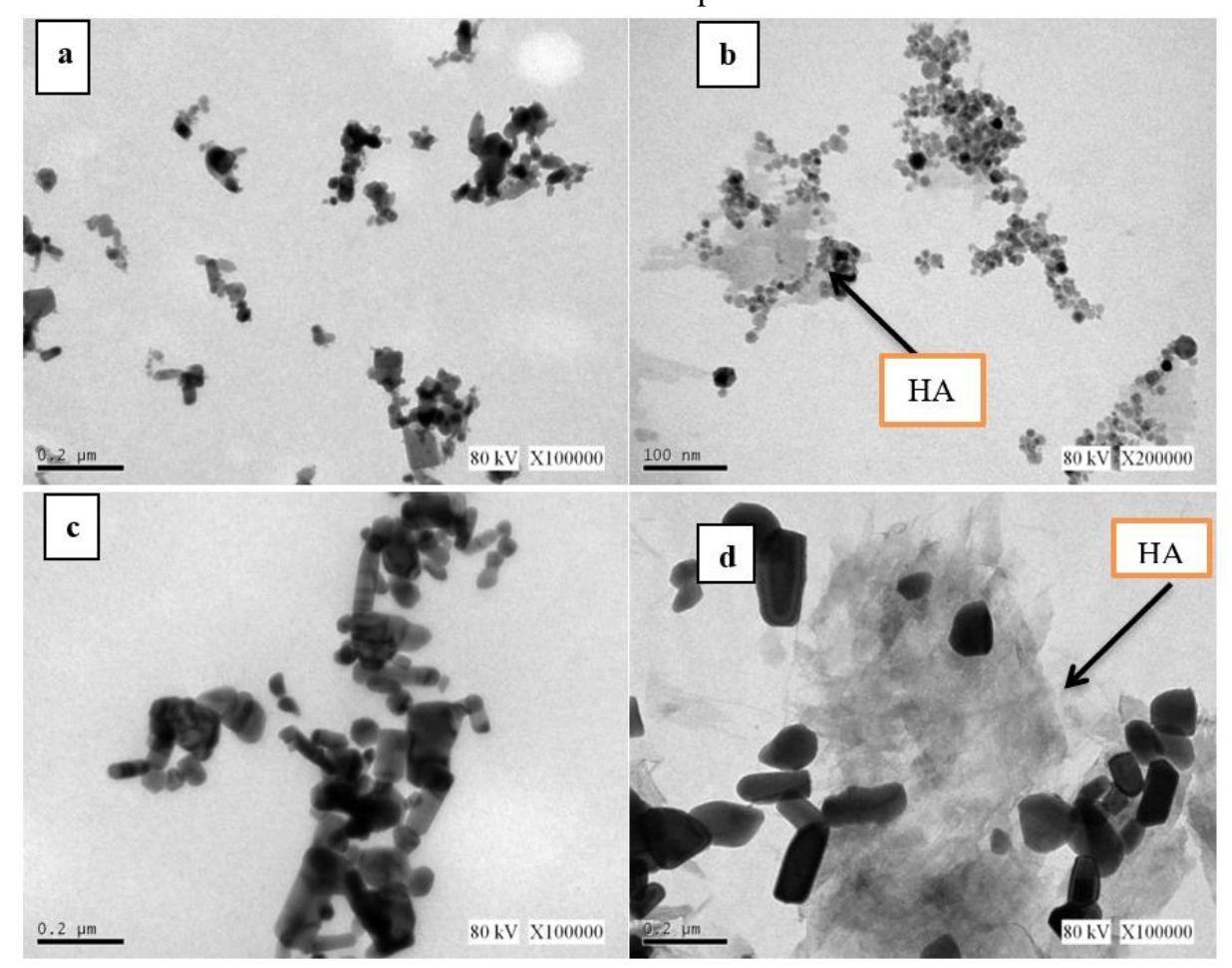

Figure 2. Complexation of $\mathrm{ZnO}$ nanoparticles when $<50 \mathrm{~nm}$ sample in the (a) absence of $\mathrm{HA}$; (b) presence of $\mathrm{HA} ;<100 \mathrm{~nm}$ sample in the (c) absence of HA; (d) presence of HA [Ionic strength $=3 \mathrm{mM}$ at $0 \mathrm{~h}$ ]. 


\subsection{Adsorption of humic acid on $\mathrm{ZnO}$ nanoparticles surface.}

Studies were carried out to determine the adsorption effect between $\mathrm{ZnO}$ nanoparticles and $\mathrm{HA}$ at different $\mathrm{pH}(\mathrm{pH} 1,3,5,7,9)$. The initial concentration of $5 \mathrm{mg} / \mathrm{L}$ of $\mathrm{HA}$ was chosen based on the total dissolved solids (HA) concentration of Paka river Terengganu, Malaysia, between 0.02 and $4.17 \mathrm{mg} / \mathrm{L}$ [24,51]. Figure 3 illustrates the amount of HA adsorbed onto the $\mathrm{ZnO}$ nanoparticles and the concentration of $\mathrm{Zn}^{2+}$ ions released during the adsorption experiment.

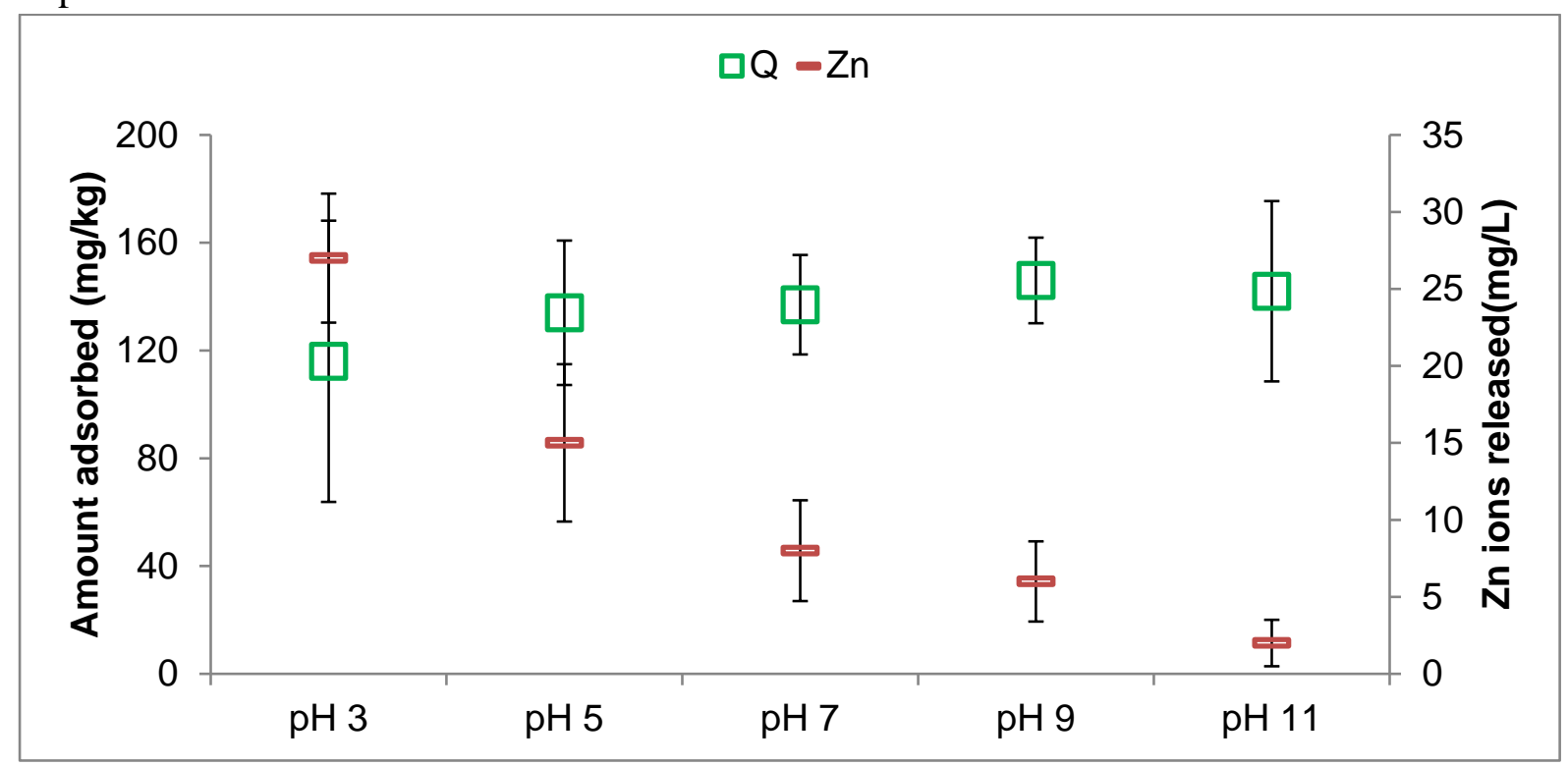

Figure 3. Amount of $\mathrm{HA}$ adsorbed onto $\mathrm{ZnO}$ nanoparticles $(\mathrm{Q})$ and concentration of $\mathrm{Zn}^{2+}$ ions released during the adsorption experiment.

From the result, increasing $\mathrm{pH}$ results in a decrease in $\mathrm{Zn}^{2+}$ ions production in the solution medium. The highest $\mathrm{Zn}^{2+}$ ion produced occurred at a $\mathrm{pH}$ of 3 with a concentration of $27 \mathrm{mg} / \mathrm{L}$, whereas, at a $\mathrm{pH}$ of 11 , only about $2 \mathrm{mg} / \mathrm{L} \mathrm{Zn}^{2+}$ ions were generated. This implies that, at higher $\mathrm{pH}$, more $\mathrm{ZnO}$ nanoparticles are present in the solution medium than their dissolved ions. A direct response exists between $\mathrm{ZnO}$ surfaces and protons in acidic conditions, causing the $\mathrm{ZnO}$ nanoparticles to dissolve more [52-54]. In a study by [55], ZnO thin films' dissolution behavior was investigated under different $\mathrm{pH}$. From their findings, the dissolution rate of the magnetron-sputtered $\mathrm{ZnO}$ thin films was moderate at $\mathrm{pH} 6$ and decreased markedly at $\mathrm{pH} 7$ increased. The trend continued to decrease to $\mathrm{pH} 10$ and finally increased with further increase in the $\mathrm{pH}$. Their result was similar to the trends observed in the $\mathrm{ZnO}$ nanoparticles used in this study. The dissociations of $\mathrm{ZnO}$ can be expressed by the following reactions suggested by $[35,52,55]$;

$$
\begin{aligned}
& \mathrm{ZnO}(\mathrm{s})+2 \mathrm{H}^{+} \leftrightarrow \mathrm{Zn}^{2+}+\mathrm{H}_{2} \mathrm{O}_{(\mathrm{l})} \\
& \mathrm{ZnO}(\mathrm{s})+\mathrm{H}^{+} \leftrightarrow \mathrm{ZnOH}^{+}
\end{aligned}
$$

As $\mathrm{pH}$ approaches neutrality (7), the $\mathrm{H}^{+}$ions decrease, thereby reducing the frequency of proton attacks. The solubility of $\mathrm{ZnO}$ nanoparticles eventually decreases as $\mathrm{pH}$ increases between $7-9$ as hydroxide groups are produced in the solution medium according to [56] with the reaction:

$$
\begin{aligned}
& \mathrm{ZnO}(\mathrm{s})+\mathrm{OH}^{-}+\mathrm{H}_{2} \mathrm{O}_{(\mathrm{l})} \leftrightarrow \mathrm{Zn}(\mathrm{OH})_{3}^{-} \\
& \mathrm{ZnO}(\mathrm{s})+2 \mathrm{OH}^{-}+\mathrm{H}_{2} \mathrm{O}_{(\mathrm{l})} \leftrightarrow \mathrm{Zn}(\mathrm{OH})_{4}^{-}
\end{aligned}
$$


Further dissolution was inhibited by the hydroxide layer formed on the $\mathrm{ZnO}$ surface under alkaline conditions. According to [55], reaction equations (3) and (4) suggest that $\mathrm{ZnO}$ formed hydroxo complexes with $\mathrm{OH}^{-}$in alkaline conditions.

On the contrary, the solubility of HA increases with increasing $\mathrm{pH}$ [42]. In this instance, more dissolved HA forms complexes on the surface of the $\mathrm{ZnO}$ nanoparticles, thereby, increasing its sorption capacity. This was depicted by the plot in Figure 3 where at a pH of 11, the maximum amount of HA adsorbed was recorded $(146 \mathrm{mg} / \mathrm{g})$. However, since less HA was dissolved at lower $\mathrm{pH}$, only a few amounts of the bulky HA $(116 \mathrm{mg} / \mathrm{g})$ could be adsorbed on the surfaces of the adsorbent. This result contradicts the study by [57]. In their study, they concluded that an increase in HA concentration and $\mathrm{pH}$ decreased the removal efficiency of $\mathrm{ZnO}$ nanoparticles in water. This resulted from the increased generation of hydrogen radicles at lower $\mathrm{pH}$, which attacked the aromatic rings of the HA to break the carbon-hydrogen bonds by the UV light, which provided the energy for this mechanism.

The adsorption isotherm of $\mathrm{HA}$ onto $\mathrm{ZnO}$ nanoparticles was also studied using Langmuir and Freundlich isotherms. The plots are illustrated in Figure 4.

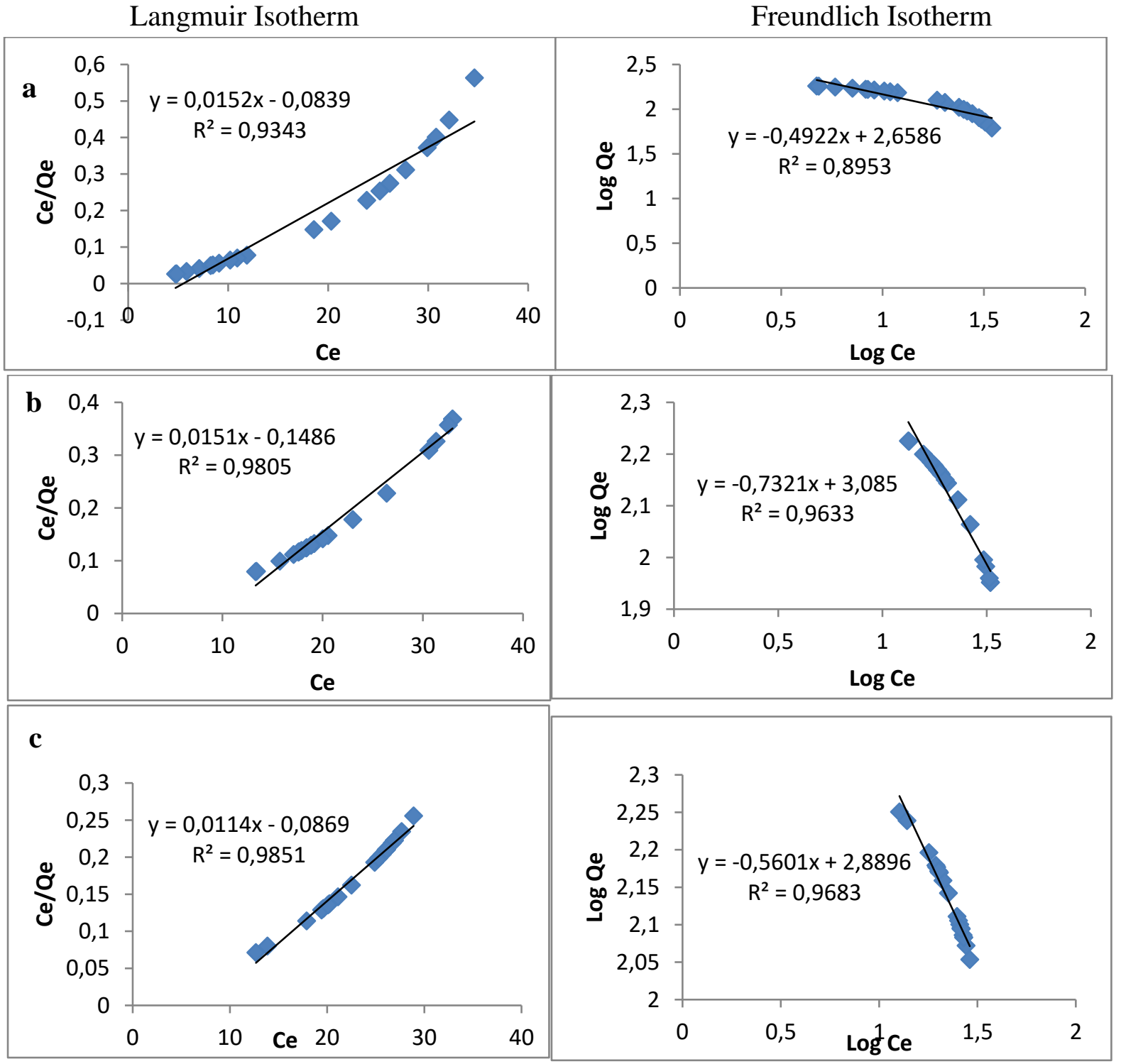




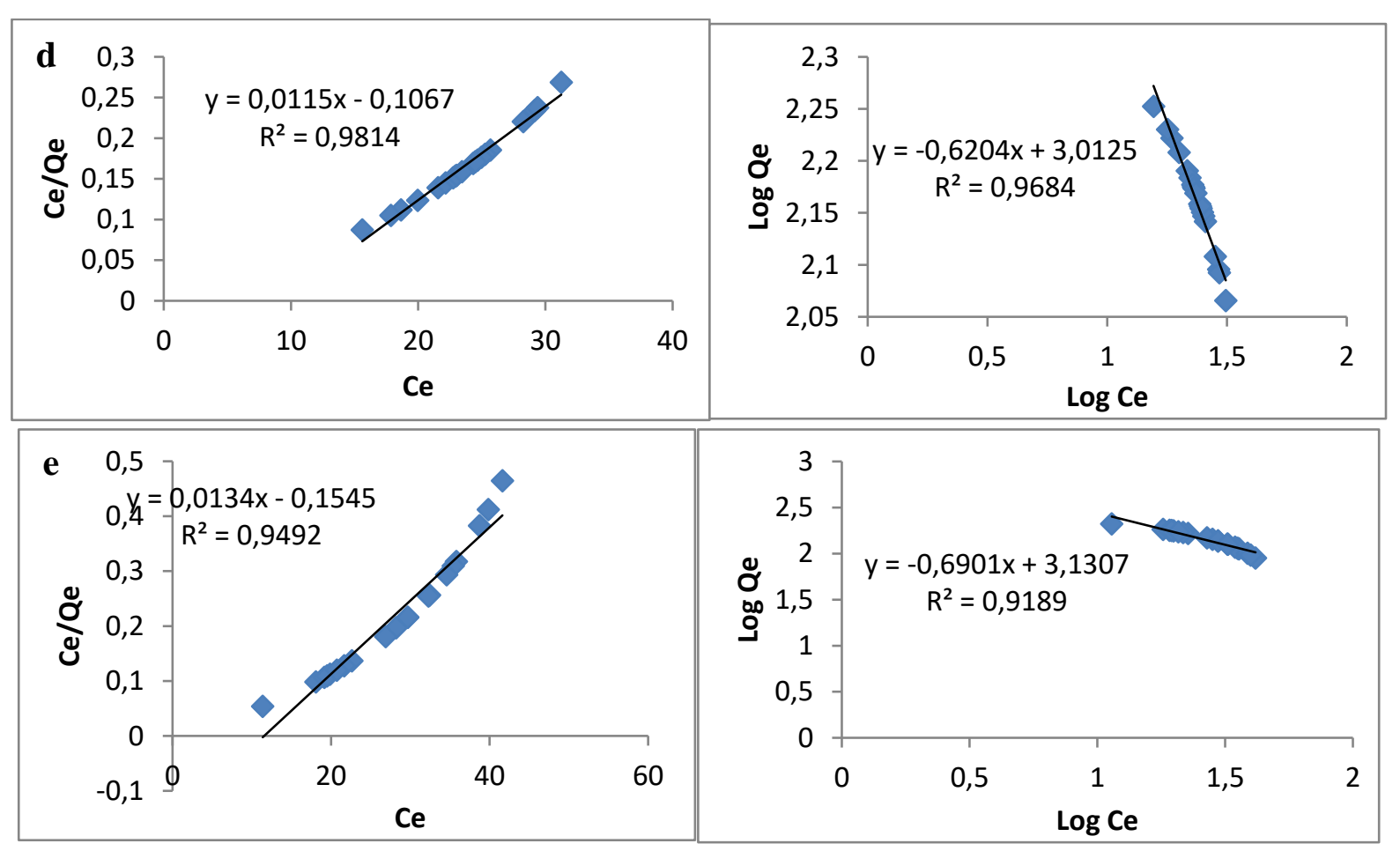

Figure 4. Graph of Langmuir and Freundlich adsorption isotherms of humic acid onto $\mathrm{ZnO}$ nanoparticles at (a) pH 3, (b) $\mathrm{pH} \mathrm{5,} \mathrm{(c)} \mathrm{pH} 7$, (d) $\mathrm{pH}$ 9; (e) $\mathrm{pH} 11$.

The constant parameters, regression correlation coefficient $\left(\mathrm{R}^{2}\right)$, and separation factors calculated for the two isotherm models are tabulated in Table 1.

Table 1. Langmuir and Freundlich isotherms fitting parameters

\begin{tabular}{l|l|l|l|l|l|l|l}
\multirow{2}{*}{ Solution pH } & \multicolumn{3}{|c|}{ Langmuir Isotherms constants } & \multicolumn{4}{|c}{ Freundlich isotherms constants } \\
\cline { 2 - 8 } & $\mathrm{R}^{2}$ & $\mathrm{~K}_{\mathrm{L}}$ & $\mathrm{R}_{\mathrm{L}}$ & $\mathrm{R}^{2}$ & $\mathrm{~K}_{\mathrm{f}}$ & $1 / \mathrm{n}$ & $\mathrm{n}$ \\
\hline 3 & 0.9343 & 65.7890 & 0.0003 & 0.8953 & 455.6170 & -2.0317 & -2.0317 \\
\hline 5 & 0.9805 & 66.2250 & 0.0002 & 0.9633 & 1216.1860 & -1.3659 & -1.3659 \\
\hline 7 & 0.9851 & 59.5200 & 0.0003 & 0.9683 & 775.5000 & -1.7853 & -1.7853 \\
\hline 9 & 0.9814 & 86.9560 & 0.0002 & 0.9684 & 1029.2000 & -1.6112 & -1.6119 \\
\hline 11 & 0.9492 & 74.626 & 0.0002 & 0.9189 & 1351.13 & 1.4490 & 1.4490
\end{tabular}

The correlation coefficient $\left(\mathrm{R}^{2}\right)$ obtained from Langmuir isotherm at all $\mathrm{pH}$ is between 0.9343 to 0.9851 compared to 0.8953 to 0.9684 recorded for Freundlich isotherm. This presupposes that the Langmuir isotherm model fits well for the adsorption process, which aligned with the study by [58]. Again, the sorption process was favorable due to the separation factor $\left(\mathrm{R}_{\mathrm{L}}\right)$, which fell between 0 and 1 . On the other hand, according to Freundlich's model, the process was unfavorable except for the dataset for $\mathrm{pH} 11$, which had its constant "n" above 1. This is because, if $n<1$, it suggests that the sorption process is unfavorable, and if $n>1$, the process is considered to be favorable $[48,59]$.

\subsection{Effect of HA on the dissolution of $\mathrm{ZnO}$ nanoparticles.}

Figure 5 shows dissolved $\mathrm{Zn}^{2+}$ ions released from two different sizes of $\mathrm{ZnO}$ nanoparticles in the presence and absence of HA at different $\mathrm{pH}$ for two days. Results show that the concentration of $\mathrm{Zn}^{2+}$ ion released from smaller sized $\mathrm{ZnO}$ nanoparticle $(<50 \mathrm{~nm})$ were higher $(67 \mathrm{mg} / \mathrm{L})$ than ions released from larger sized $\mathrm{ZnO}$ nanoparticles $(<100 \mathrm{~nm})$ of 13 $\mathrm{mg} / \mathrm{L}$ at $\mathrm{pH} 1$ for both samples. In the presence and absence of HA for the smaller $\mathrm{ZnO}$ nanoparticles $(<50 \mathrm{~nm})$, dissolution decreases with increasing $\mathrm{pH}$ for days 1 and 2 . In the case of the larger particle size $(<100 \mathrm{~nm})$, dissolution decreased from $\mathrm{pH} 1$ to $\mathrm{pH} 7$. Eventually, it 
increased to about $28 \mathrm{mg} / \mathrm{L}$ for days 1 and 2 in the presence of HA. However, in the absence of $\mathrm{HA}$, the decreased dissolution began from $\mathrm{pH} 1$ to $\mathrm{pH} 6$, peaked at $\mathrm{pH} 7$, and finally decreased in $\mathrm{pH}$ 9. This result is in line with a study by [60], which attributed the higher dissolution to agglomeration and sedimentation.

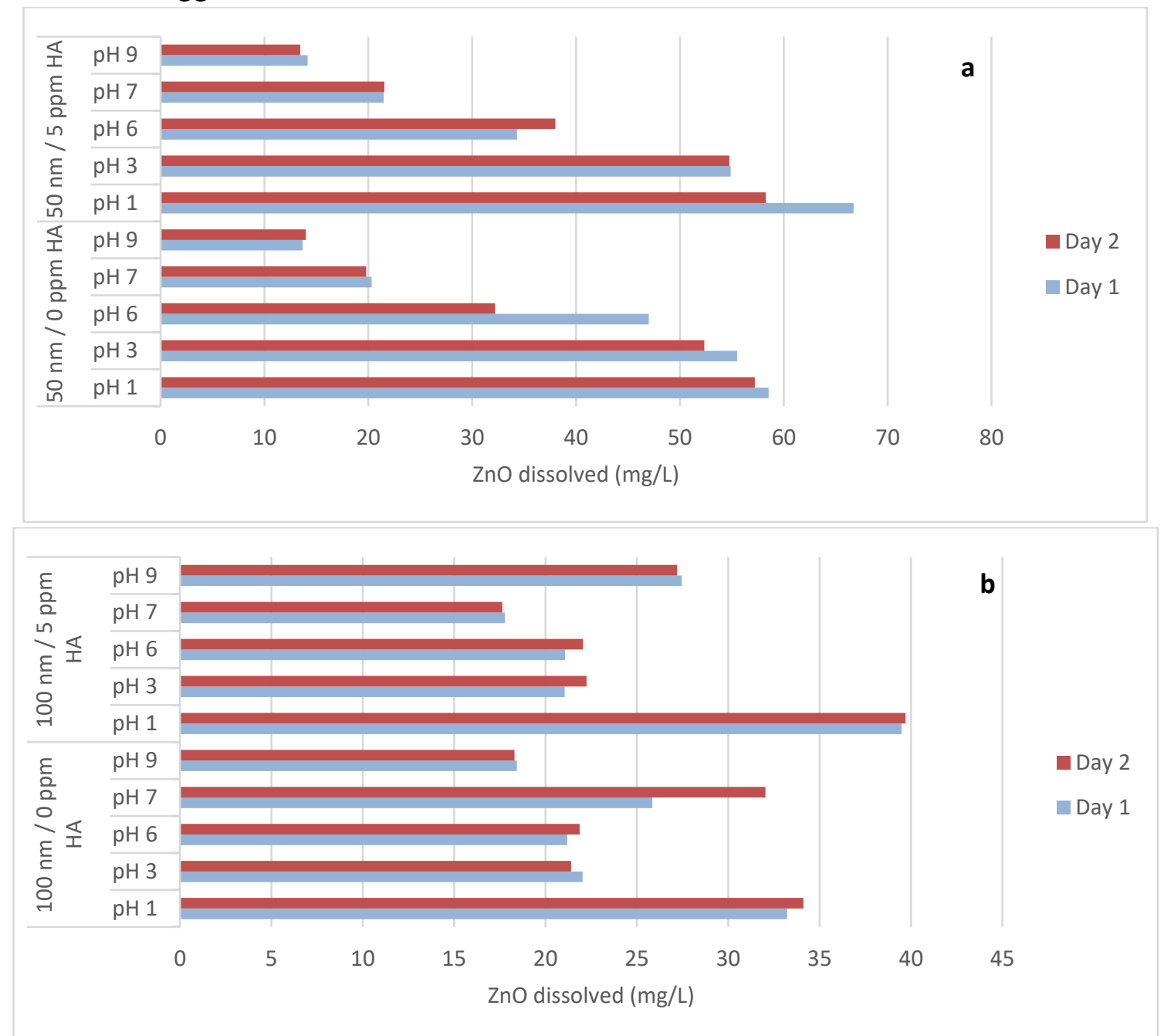

Figure 5. Dissolution of $\mathrm{ZnO}$ nanoparticles; (a) $<50 \mathrm{~nm}$; (b) $<100 \mathrm{~nm}$ in the presence and absence of HA at different $\mathrm{pH}$ conditions for two days; ionic strength $=3 \mathrm{mM} \mathrm{NaCl}$.

This finding was also in agreement with previous studies by [54]. More than $53 \%$ of $\mathrm{ZnO}$ nanoparticles were dissolved as $\mathrm{Zn}^{2+}$ ions at $\mathrm{pH} 3-6$. However, at $\mathrm{pH} 8-11$, the $\mathrm{ZnO}$ nanoparticles' solubility was reduced to less than 5\%. According to [54], adsorption of HA on $\mathrm{ZnO}$ nanoparticle surfaces reduces the particles' surface potential due to negatively charged HA. Meanwhile, it was reported that HA increased the dissolution of $\mathrm{ZnO}$ at high $\mathrm{pH}$ (9 and 11) as bonding between the HA and the sorbate ions lose their polarity [61]. Previous studies regarding the effect of size and dissolution have been carried out. However, there is less study that involves different $\mathrm{pH}$ when HA present. TEM images in Figure $3 \mathrm{a}$ and $3 \mathrm{c}$ shows how this size-factor related to the solubility of particles. Larger sized particles $(<100 \mathrm{~nm})$ are less soluble than smaller sized particles $(<50 \mathrm{~nm})$, and this is shown when they tend to aggregate with themselves.

\subsection{Effect of sunlight on the dissolution of $\mathrm{ZnO}$ nanoparticles.}

Figure 6 shows the effect of sunlight in the dissolution of $\mathrm{ZnO}$ nanoparticles $(<50 \mathrm{~nm}$ and $<100 \mathrm{~nm}$ ) in the (a) presence and (b) absence of HA at a specific $\mathrm{pH}$ of 7 and ionic strength 
(I) of $3 \mathrm{mM} \mathrm{NaCl}$. The $<50 \mathrm{~nm}$ and $<100 \mathrm{~nm} \mathrm{ZnO}$ nanoparticles were more stable in the presence of sunlight and HA than in the absence of sunlight and HA. The dissolution of the two $\mathrm{ZnO}$ samples $(<50 \mathrm{~nm}$ and $<100 \mathrm{~nm})$ in the presence of HA and sunlight remains constant in the range of $21.41-21.83 \mathrm{mg} / \mathrm{L}$ and $17.53-17.77 \mathrm{mg} / \mathrm{L}$, respectively. However, the smaller particles $(<50 \mathrm{~nm})$ in the presence of HA with no sunlight saw an increase in $\mathrm{Zn}^{2+}$ ion release within the first 4 hours of irradiation with a maximum yield of $28.07 \mathrm{mg} / \mathrm{L}$. This then decreased gradually to $9.37 \mathrm{mg} / \mathrm{L}$ at the $32^{\text {nd }}$ hour of irradiation.

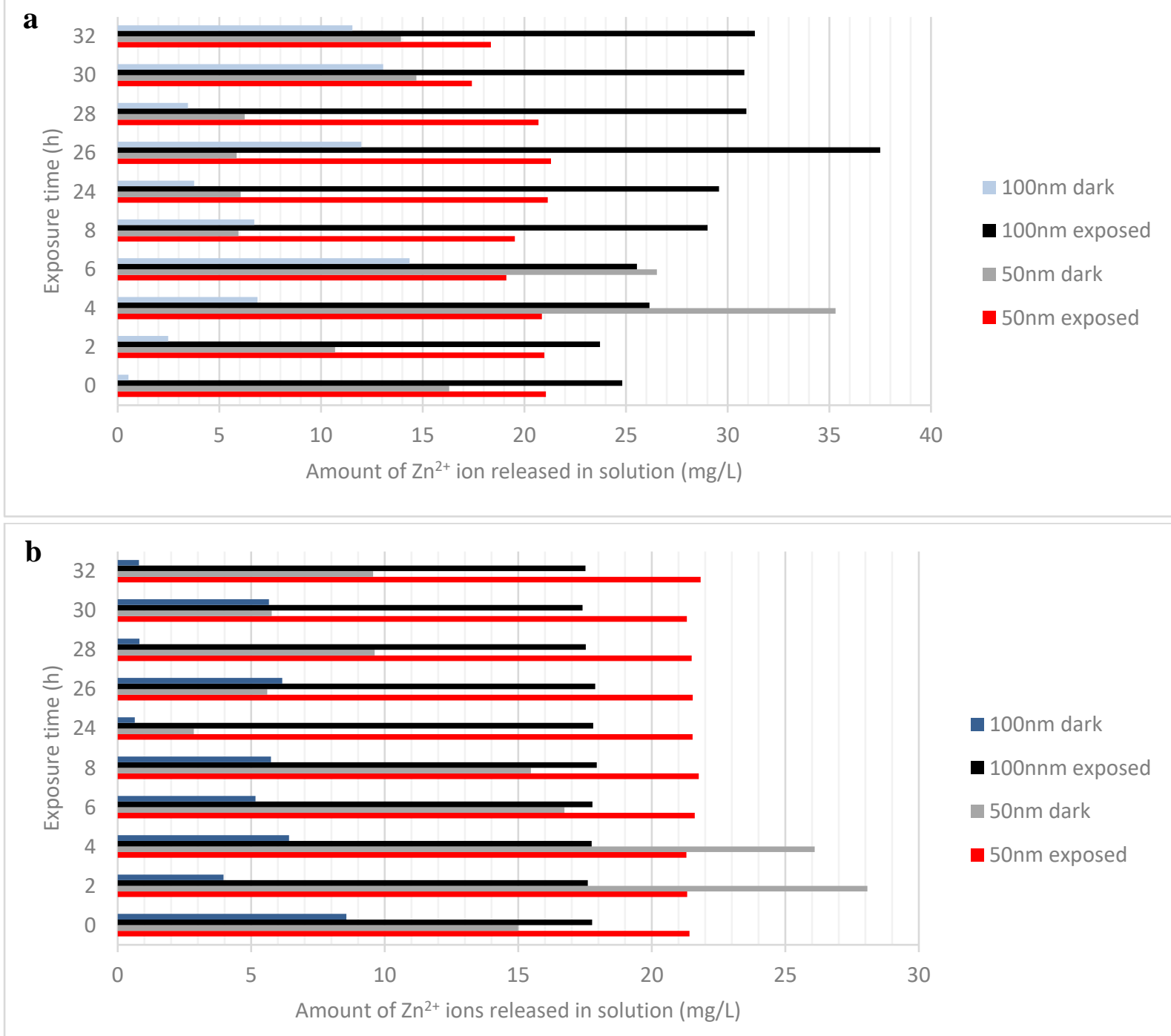

Figure 6. Effect of sunlight in the dissolution of $\mathrm{ZnO}$ nanoparticles at $\mathrm{pH} 7$ in (a) $\mathrm{HA}=0 \mathrm{mg} / \mathrm{L} ;(\mathbf{b}) \mathrm{HA}=5$ $\mathrm{mg} / \mathrm{L}, \mathrm{I}=3 \mathrm{mM} \mathrm{NaCl}$.

In the absence of sunlight, the smaller $\mathrm{ZnO}$ nanoparticles $(<50 \mathrm{~nm})$ increased in their dissolutions in the presence and absence of HA for the first 4 hours of irradiation and gradually decreased. The maximum concentrations of $\mathrm{Zn}^{2+}$ generated in solution in the absence and presence of HA were $35.31 \mathrm{mg} / \mathrm{L}$ and $28.07 \mathrm{mg} / \mathrm{L}$, respectively. However, in the absence of sunlight, dissolution of $<100 \mathrm{~nm} \mathrm{ZnO}$ sample to produce $\mathrm{Zn}^{2+}$ ions fluctuated in the presence and absence of HA for the entire 32 hours of irradiation. The maximum concentration of $\mathrm{Zn}^{2+}$ ions produced in the absence and presence of $\mathrm{HA}$ is $14.36 \mathrm{mg} / \mathrm{L}$ and $8.57 \mathrm{mg} / \mathrm{L}$ at the $6^{\text {th }}$ and $1^{\text {st }}$ hour of irradiation. The dissolution of $\mathrm{ZnO}$ nanoparticles in this study is in line with a study by [60], where maximum dissolution was recorded at lower $\mathrm{pH}$ (4.8-6.5). Also, visible and UV-light facilitated the dissolution of $\mathrm{ZnO}$ nanoparticles in their study. In contrast, our study 
reported higher dissolution in the case of larger particle size $(<100 \mathrm{~nm})$ in the absence of HA. Han et al. also proposed the photocatalytic reaction that influenced the dissolution process as follow:

$\begin{array}{ll}\mathrm{ZnO}_{(\mathrm{s})}+\mathrm{h} v \rightarrow \mathrm{ZnO}_{(\mathrm{s})}+\mathrm{h}^{+}+\mathrm{e}^{-} & \text {(photocatalysis) } \\ \mathrm{h}^{+}+\mathrm{e}^{-} \rightarrow \mathrm{h} v \text { (or heat) } & \text { (re-combination) }\end{array}$ (re-combination)

$\mathrm{ZnO}_{(\mathrm{s})}+2 \mathrm{~h}^{+} \rightarrow \mathrm{Zn}^{2+}{ }_{(\mathrm{aq})}+\frac{1}{2} \mathrm{O}_{2} \quad$ ( $\mathrm{ZnO}$ photo-dissolution)

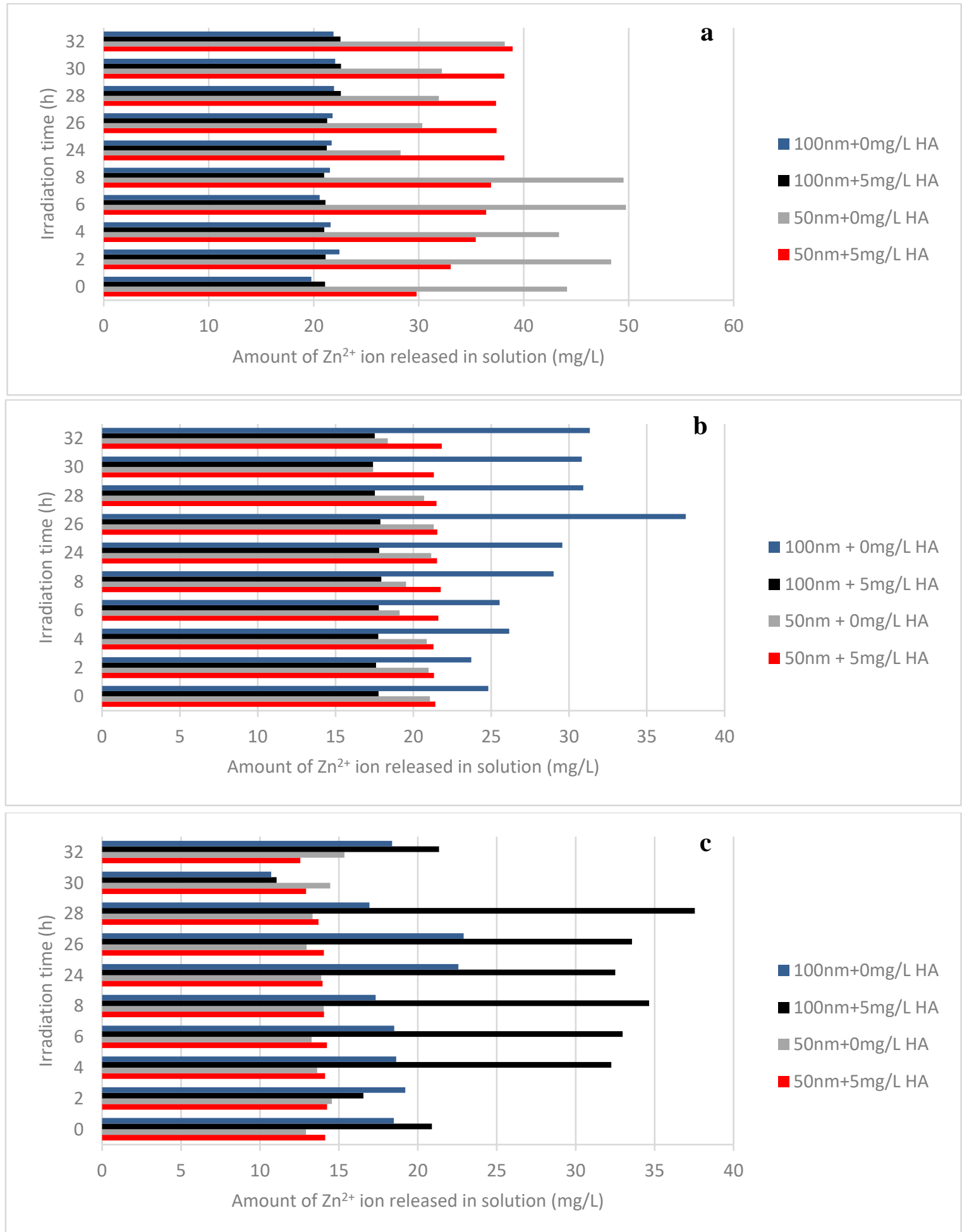

Figure 7. Effect of $\mathrm{HA}$ and irradiation time on dissolution of $\mathrm{ZnO}$ nanoparticles at (a) $\mathrm{pH} 6$; (b) pH 7; (c) pH 9 for and period of 32 hours $[\mathrm{I}=3 \mathrm{mM} \mathrm{NaCl}]$.

To study the effect of HA in the dissolution of $\mathrm{ZnO}$ nanoparticles, $\mathrm{pH} 6, \mathrm{pH}$ 7, and $\mathrm{pH}$ 9 was chosen since it was a representation of the natural environmental conditions of fresh https://biointerfaceresearch.com/ 
surface water (6.5-8.5) and underground water (6-8.5) from the National Water Quality Standards for Malaysia (EQR2006 source).

Figure 7 illustrates the effect of HA, irradiation time on the dissolution of the two $\mathrm{ZnO}$ nanoparticle samples at different $\mathrm{pH}$ values $(6,7$, and 9).

The stability of dissolution of each $\mathrm{ZnO}$ nanoparticles at the different $\mathrm{pH}$ varies from the different conditions available for each particle. At pH 6, the larger particle size $(<100 \mathrm{~nm})$ in the presence and absence of HA were stable in the ion production as compared to the smaller particles $(<50 \mathrm{~nm})$, which increased in $\mathrm{Zn}^{2+}$ ion production with an increase in irradiation time. The maximum concentration of $\mathrm{Zn}^{2+}$ ion produced was $38.95 \mathrm{mg} / \mathrm{L}$ and $49.94 \mathrm{mg} / \mathrm{L}$ for $\mathrm{ZnO}$ nanoparticles in the presence and absence of HA. At pH 7, apart from $<100 \mathrm{~nm}$ in the absence of HA, the rest of the test samples were stable in their ion production in an aqueous solution. The stabilized $\mathrm{Zn}^{2+}$ ion concentration was in the range of $17.77-21.83 \mathrm{mg} / \mathrm{L}$. The maximum concentration of $\mathrm{Zn}^{2+}$ ion released by the $<100 \mathrm{~nm} \mathrm{ZnO}$ nanoparticles in the absence of HA was $37.50 \mathrm{mg} / \mathrm{L}$ at the $26^{\text {th }}$ irradiation time. Larger $\mathrm{ZnO}$ nanoparticles $(<100 \mathrm{~nm})$ recorded their maximum $\mathrm{Zn}^{2+}$ ions concentration $(37.55 \mathrm{mg} / \mathrm{L})$ in $\mathrm{pH}$ 9. The other samples recorded a stable $\mathrm{Zn}^{2+}$ ion concentration both in the presence and absence of HA. This result is in line with a study by [56]. They reported that the solubility of larger-sized $\mathrm{ZnO}$ nanoparticles $(n-\mathrm{ZnO}-1)$ to produce $\mathrm{Zn}^{2+}$ ions increased with an increase in HA in a solution of $\mathrm{pH} 9$. The difference might be due to sunlight's presence where the HA may have been photo-degraded due to the electron-hole-pair generated from $\mathrm{ZnO}$ nanoparticles when irradiated with sunlight [62]. Literature reported three mechanisms that occur when HA adsorb onto metal oxide nanomaterial surfaces. First, the uniquely high specific surface area of nanoparticles provides HA with a large adsorption space. Secondly, accessibility of the HA molecules to the sites with low hydrophilicity and low negative charge on the particle surface. Finally, the HA adsorption occurs due to the electrostatic attraction and ligand exchange reactions between $\mathrm{HA}$ and oxide materials [56].

In comparing the TEM images in Figure $2 b$ and $2 d$, smaller particles aggregate more in the presence of HA than their larger particles. Although the aggregates tend to present a larger surface area, their interaction with HA hinders their dissolution due to the strong complexation. Previous studies on cerium dioxide interaction with HA concluded that, whenever organic molecules adhere to cerium dioxides, they provide a barrier to aggregation and more dispersion [63].

\section{Conclusions}

The effects of sunlight and HA on the behavior of $\mathrm{ZnO}$ nanoparticles were studied. In the presence of $\mathrm{HA}$, the dissolution of $\mathrm{ZnO}$ nanoparticles was higher than the absence of HA. This is because the negative charge of HA changes $\mathrm{ZnO}$ nanoparticles' surface charge, preventing the particles from aggregating and precipitating. When exposed to sunlight without $\mathrm{HA}$, the dissolution is stable over the irradiation time. In a combination of both sunlight and $\mathrm{HA}$, the $\mathrm{Zn}^{2+}$ ions released doubled as much as without HA. The sorption process of HA onto $\mathrm{ZnO}$ nanoparticles was favorable and fitted well by the Langmuir isotherm model.

On the other hand, according to Freundlich's model, the process was unfavorable except for the dataset for $\mathrm{pH} 11$, which had its constant " $\mathrm{n}$ " above 1. In conclusion, both factors influenced the $\mathrm{ZnO}$ nanoparticles' fate and enhanced the release of $\mathrm{Zn}^{2+}$ over time in an aqueous environment. This study also indicates that the fate of $\mathrm{ZnO}$ nanoparticles is highly dependent on water chemistry. At higher $\mathrm{pH}$, the dissolution of $\mathrm{ZnO}$ was limited by solubility 
equilibrium [60]. The $\mathrm{pH}$ value a dominant factor, together with sunlight facilitating the $\mathrm{ZnO}$ dissolution most probably by degrading the HA.

\section{Funding}

This research was supported by the Ministry of Higher Education FRGS/ST01(01)/1208/2014(09) and Universiti Malaysia Sarawak, Tun Openg Chair, F07/TOC/1738/2018.

\section{Acknowledgments}

The authors would like to thank colleagues from the Faculty of Resource Science and Technology (FRST), Geochemistry laboratory, Universiti Malaysia Sarawak.

\section{Conflicts of Interest}

The authors declare that they have no competing interests regarding the publication of this manuscript. Also, issues of plagiarism, data fabrication and or falsification, double publication, and or submission have been completely observed by the authors. VA Velintine and BS Wee designed the research. VA Velintine carried out the laboratory work. BS Wee, EK Droepenu, SF Chin, and KY Kok conducted the review and editing. Finally, all authors have read and approved the manuscript for publication.

\section{References}

1. Ali, I.; Peng, C.; Khan, Z.M.; Naz, I.; Sultan, M.; Ali, M.; Abbasi, I.A.; Islam, T.; Ye, T. Overview of microbes based fabricated biogenic nanoparticles for water and wastewater treatment. Journal Environmental Management 2019, 230, 128-150, https://doi.org/10.1016/j.jenvman.2018.09.073.

2. Zhu, L.; Li, H.; Xia, P.; Liu, Z.; Xiong, D. Hierarchical ZnO Decorated with $\mathrm{CeO} 2$ Nanoparticles as the Direct Z-Scheme Heterojunction for Enhanced Photocatalytic Activity. ACS Applied Materials \& Interfaces 2018, 10, 39679-39687, https://doi.org/10.1021/acsami.8b13782.

3. Hoang Thi, T.T.; Cao, V.D.; Nguyen, T.N.Q.; Hoang, D.T.; Ngo, V.C.; Nguyen, D.H. Functionalized mesoporous silica nanoparticles and biomedical applications. Materials Science and Engineering: $C$ 2019, 99, 631-656, https://doi.org/10.1016/j.msec.2019.01.129.

4. Pang, W.Y.; Ahmad, A.L.; Zaulkiflee, N.D. Antifouling and antibacterial evaluation of ZnO/MWCNT dual nanofiller polyethersulfone mixed matrix membrane. Journal Environmental Management 2019, 249, 109358, https://doi.org/10.1016/j.jenvman.2019.109358.

5. Besha, A.T.; Liu, Y.; Bekele, D.N.; Dong, Z.; Naidu, R.; Gebremariam, G.N. Sustainability and environmental ethics for the application of engineered nanoparticles. Environmental Science \& Policy 2020, 103, 85-98, https://doi.org/10.1016/j.envsci.2019.10.013.

6. Yu, J.; Jiang, C.; Guan, Q.; Ning, P.; Gu, J.; Chen, Q.; Zhang, J.; Miao, R. Enhanced removal of Cr(VI) from aqueous solution by supported $\mathrm{ZnO}$ nanoparticles on biochar derived from waste water hyacinth. Chemosphere 2018, 195, 632-640, https://doi.org/10.1016/j.chemosphere.2017.12.12.

7. Danielsson, K.; Gallego-Urrea, J.A.; Hassellov, M.; Gustafsson, S.; Jonsson, C.M. Influence of organic molecules on the aggregation of $\mathrm{TiO} 2$ nanoparticles in acidic conditions. Journal of Nanoparticle Research 2017, 19, 133, http://doi.org/10.1007/s11051-017-3807-9.

8. Arenas-Lago, D.; Monikh, F.A.; Vijver, M.G.; Peijnenburg, W.J. Dissolution and aggregation kinetics of zero valent copper nanoparticles in (simulated) natural surface waters: Simultaneous effects of $\mathrm{pH}$, NOM and ionic strength. Chemosphere 2019, 226, 841-850, https://doi.org/10.1016/j.chemosphere.2019.03.190.

9. Najim, N.; Rusdi, R.; Hamzah, A.S.; Shaameri, Z.; Mat Zain, M.; Kamarulzaman, N. Effects of the absorption behaviour of $\mathrm{ZnO}$ nanoparticles on cytotoxicity measurements. Journal of Nanomaterials 2014, 2014, http://doi.org/10.1155/2014/694737.

10. Carbery, M.; O'Connor, W.; Palanisami, T. Trophic transfer of microplastics and mixed contaminants in the marine food web and implications for human health. Environment International 2018, 115, 400-409, https://doi.org/10.1016/j.envint.2018.03.007.

11. Jia, H.-R.; Zhu, Y.-X.; Duan, Q.-Y.; Chen, Z.; Wu, F.-G. Nanomaterials meet zebrafish: Toxicity evaluation and drug delivery applications. Journal Controlled Release 2019, 311-312, 301-318, https://doi.org/10.1016/j.jconrel.2019.08.022. 
12. Dekkers, S.; Ma-Hock, L.; Lynch, I.; Russ, M.; Miller, M.R.; Schins, R.P.F.; Keller, J.; Römer, I.; Küttler, K.; Strauss, V.; De Jong, W.H.; Landsiedel, R.; Cassee, F.R. Differences in the toxicity of cerium dioxide nanomaterials after inhalation can be explained by lung deposition, animal species and nanoforms. Inhalation Toxicology. 2018, 30, 273-286, https://doi.org/10.1080/08958378.2018.1516834.

13. Oliveira, A.G.; Andrade, J.d.L.; Montanha, M.C.; Lima, S.M.; Andrade, L.H.d.C.; Winkler Hechenleitner, A.A.; Pineda, E.A.G.; Oliveira, D.M.F.d. Decontamination and disinfection of wastewater by photocatalysis under UV/visible light using nano-catalysts based on Ca-doped ZnO. Journal of Environmental Management 2019, 240, 485-493, https://doi.org/10.1016/j.jenvman.2019.03.124.

14. Liu, Z.; Wang, C.; Hou, J.; Wang, P.; Miao, L.; Lv, B.; Yang, Y.; You, G.; Xu, Y.; Zhang, M.; Ci, H. Aggregation, sedimentation, and dissolution of $\mathrm{CuO}$ and $\mathrm{ZnO}$ nanoparticles in five waters. Environmental Science and Pollution Research 2018, 25, 31240-31249, https://doi.org/10.1007/s11356-018-3123-7.

15. Sengul, A.B.; Asmatulu, E. Toxicity of metal and metal oxide nanoparticles: a review. Environmental Chemistry Letters 2020, 18, 1659-1683, https://doi.org/10.1007/s10311-020-01033-6.

16. Wahab, R.; Khan, F.; Lutfullah; Singh, R.B.; Kaushik, N.K.; Ahmad, J.; Siddiqui, M.A.; Saquib, Q.; Ali, B.A.; Khan, S.T.; Musarrat, J.; Al-Khedhairy, A.A. Utilization of photocatalytic ZnO nanoparticles for deactivation of safranine dye and their applications for statistical analysis. Physica E: Low-dimensional Systems and Nanostructures 2015, 69, 101-108, https://doi.org/10.1016/j.physe.2015.01.005.

17. Jiang, J.; Pi, J.; Cai, J. The advancing of zinc oxide nanoparticles for biomedical applications. Bioinorganic Chemistry \& Applications 2018, 2018, https://doi.org/10.1155/2018/1062562.

18. Wahab, R.; Khan, F.; Mishra, Y.K.; Musarrat, J.; Al-Khedhairy, A.A. Antibacterial studies and statistical design set data of quasi zinc oxide nanostructures. RSC Advances 2016, 6, 32328-32339, https://doi.org/10.1039/C6RA05297E.

19. Sirelkhatim, A.; Mahmud, S.; Seeni, A.; Kaus, N.H.M.; Ann, L.C.; Bakhori, S.K.M.; Hasan, H.; Mohamad, D. Review on Zinc Oxide Nanoparticles: Antibacterial Activity and Toxicity Mechanism. Nano-Micro Letters 2015, 7, 219-242, https://doi.org/10.1007/s40820-0150040-x.

20. Areerachakul, N.; Sakulkhaemaruethai, S.; Johir, M. A. H.; Kandasamy, J.; Vigneswaran, S. Photocatalytic degradation of organic pollutants from wastewater using aluminium doped titanium dioxide. Journal of Water Process Engineering 2019, 27, 177-184, https://doi.org/10.1016/j.jwpe.2018.12.006.

21. Birben, N.C.; Paganini, M.C.; Calza, P.; Bekbolet, M. Photocatalytic degradation of humic acid using a novel photocatalyst: Ce-doped ZnO. Photochemical \& Photobiological Sciences 2017, 16, 24-30, https://doi.org/10.1039/C6PP00216A.

22. Bel Hadjltaief, H.; Ben Zina, M.; Galvez, M.E.; Da Costa, P. Photocatalytic degradation of methyl green dye in aqueous solution over natural clay-supported $\mathrm{ZnO}-\mathrm{TiO} 2$ catalysts. Journal of Photochemistry \& Photobiology A: Chemistry 2016, 315, 25-33, https://doi.org/10.1016/j.jphotochem.2015.09.008.

23. Philippe, A.; Schaumann, G.E. Interactions of Dissolved Organic Matter with Natural and Engineered Inorganic Colloids: A Review. Environmental Science \& Technology 2014, 48, 8946-8962, http://doi.org/10.1021/es502342r.

24. Dziedzic, J.; Wodka, D.; Nowak, P.; Warszyński, P.; Simon, C.; Kumakiri, I. Photocatalytic degradation of the humic species as a method of their removal from water - comparison of UV and artificial sunlight irradiation. Physicochemical Problems of Mineral Processing 2010, 45(1), 15-28.

25. Ghaneian, M.T.; Morovati, P.; Ehrampoush, M.H.; Tabatabaee, M. Humic acid degradation by the synthesized flower-like $\mathrm{Ag} / \mathrm{ZnO}$ nanostructure as an efficient photocatalyst. Journal of Environmental Health Science and Engineering 2014, 12, 138, http://doi.org/10.1186/s40201-014-0138-y.

26. Tang, W.-W.; Zeng, G.-M.; Gong, J.-L.; Liang, J.; Xu, P.; Zhang, C.; Huang, B.-B. Impact of humic/fulvic acid on the removal of heavy metals from aqueous solutions using nanomaterials: A review. Science of the Total Environment 2014, 468-469, 1014-1027, http://dx.doi.org/10.1016/j.scitotenv.2013.09.044.

27. Wang, J.; Zhou, Y.; Li, A.; Xu, L. Adsorption of humic acid by bi-functional resin JN-10 and the effect of alkali-earth metal ions on the adsorption. Journal of Hazardous Materials 2010, 176, 1018-1026, https://doi.org/10.1016/j.jhazmat.2009.11.142.

28. Maiga, D.T.; Nyoni, H.; Nkambule, T.T.; Mamba, B.B.; Msagati, T.A.M. Impact of zinc oxide nanoparticles in aqueous environments: influence of concentrations, natural organic matter and ionic strength. Inorganic and Nano-Metal Chemistry 2020, 50, 680-692, https://doi.org/10.1080/24701556.2020.1724145.

29. Zhao, Y.; Zhou, W.; Wang, Y.; Gao, B.; Xu, X.; Zhao, Y. The effect of humic acid and bovine serum albumin on the adsorption and stability of $\mathrm{ZnO}$ nanoparticles on powdered activated carbon. Journal of Cleaner Production 2020, 251, 119695, https://doi.org/10.1016/j.jclepro.2019.119695.

30. Huang, J.; Liu, S.; Kuang, L.; Zhao, Y.; Jiang, T.; Liu, S.; Xu, X. Enhanced photocatalytic activity of quantum-dot-sensitized one-dimensionally-ordered $\mathrm{ZnO}$ nanorod photocatalyst. Journal of Environmental Sciences 2013, 25, 2487-2491, http://doi.org/10.1016/S1001-0742(12)60330-1.

31. Shirzad Siboni, M.; Samadi, M.T.; Yang, J.K.; Lee, S.M. Photocatalytic reduction of Cr(VI) and Ni(II) in aqueous solution by synthesized nanoparticle $\mathrm{ZnO}$ under ultraviolet light irradiation: a kinetic study. Environmental Technology 2011, 32, 1573-1579, http://doi.org/10.1080/09593330.201. 
32. Zhou, J.; Xu, N.S.; Wang, Z.L. Dissolving Behavior and Stability of ZnO Wires in Biofluids: A Study on Biodegradability and Biocompatibility of ZnO Nanostructures. Advanced Materials 2006, 18, 2432-2435, https://doi.org/10.1002/adma.200600200.

33. Liu, W.; Li, Y.; Liu, F.; Jiang, W.; Zhang, D.; Liang, J. Visible-light-driven photocatalytic degradation of diclofenac by carbon quantum dots modified porous g-C3N4: Mechanisms, degradation pathway and DFT calculation. Water Research 2019, 151, 8-19, https://doi.org/10.1016/j.watres.2018.11.084.

34. Ma, H.; Brennan, A.; Diamond, S.A. Photocatalytic reactive oxygen species production and phototoxicity of titanium dioxide nanoparticles are dependent on the solar ultraviolet radiation spectrum. Environmental Toxicology \& Chemistry 2012, 31, 2099-2107, http://doi.org/10.1002/etc.1916.

35. Bian, S.-W.; Mudunkotuwa, I.A.; Rupasinghe, T.; Grassian, V.H. Aggregation and Dissolution of $4 \mathrm{~nm} \mathrm{ZnO}$ Nanoparticles in Aqueous Environments: Influence of pH, Ionic Strength, Size, and Adsorption of Humic Acid. Langmuir 2011, 27, 6059-6068, https://doi.org/10.1021/la200570n.

36. Neale, P.A.; Jämting, A.K.; O’Malley, E.; Herrmann, J.; Escher, B.I. Behaviour of titanium dioxide and zinc oxide nanoparticles in the presence of wastewater-derived organic matter and implications for algal toxicity. Environmental Science: Nano 2015, 2, 86-93, http://doi.org/10.1039/C4EN00161C.

37. Peng, Y.-H.; Tso, C.-p.; Tsai, Y.-c.; Zhuang, C.-m.; Shih, Y.-h. The effect of electrolytes on the aggregation kinetics of three different $\mathrm{ZnO}$ nanoparticles in water. Science of the Total Environment 2015, 530-531, 183190, http://doi.org/10.1016/j.scitotenv.2015.05.059,

38. Peng, Y.-H.; Tsai, Y.-C.; Hsiung, C.-E.; Lin, Y.-H.; Shih, Y.-h. Influence of water chemistry on the environmental behaviors of commercial $\mathrm{ZnO}$ nanoparticles in various water and wastewater samples. Journal of Hazardous Materials 2017, 322, 348-356, http://doi.org/10.1016/j.jhazmat.2016.10.003.

39. Degenkolb, L.; Kaupenjohann, M.; Klitzke, S. The Variable Fate of Ag and TiO 2 Nanoparticles in Natural Soil Solutions-Sorption of Organic Matter and Nanoparticle Stability. Water, Air, \& Soil Pollution 2019, 230, 1-14, https://doi.org/10.1007/s11270-019-4123-z.

40. Velintine, V.; Siong, W.B.; Chin, S.; Kok, K.Y. Transformation of zinc oxide nanoparticles under environmentally relevant conditions: influence of $\mathrm{pH}$ and ionic strength. Transactions on Science and Technology 2017, 4(2), 123-136, http://tost.unise.org/pdfs/vol4/no2/4x2x123x136.pdf

41. Zhu, M.; Wang, H.; Keller, A.A.; Wang, T.; Li, F. The effect of humic acid on the aggregation of titanium dioxide nanoparticles under different $\mathrm{pH}$ and ionic strengths. Science of the Total Environment 2014, 487, 375-380, https://doi.org/10.1016/j.scitotenv.2014.04.036.

42. Wang, Z.; Cao, M.; Cai, W.; Zeng, H. The effect of humic acid and fulvic acid on adsorption-desorption behavior of copper and zinc in the yellow soil. AIP Conference Proceedings. 2017, 1820, 040027, https://doi.org/10.1063/1.4977299.

43. Asgari, G.; Ebrahimi, A.; Mohammadi, A.; Ghanizadeh, G. The investigation of humic acid adsorption from aqueous solutions onto modified pumice with hexadecyl trimethyl ammonium bromide. International Journal of Environmental Health Engineering 2013, 2, 20-20, https://doi.org/10.4103/2277-9183.110176.

44. Javanshah, A.; Saidi, A. Determination of humic acid by spectrophotometric analysis in the soils. International Journal of Advanced Biotechnology and Research 2016, 7, 19-23.

45. Herbert, N.; Affonso Celso, G.; Marcelo Angelo, C.; Gustavo Ferreira, C.; Daniel, S.; Marcelo Gonçalves dos, S.; Dionir Luiz, B.; Juliano, Z. Adsorption of Cu (II) and Zn (II) from Water by Jatropha curcas L. as Biosorbent. Open Chemistry 2016, 14, 103-117, https://doi.org/10.1515/chem-2016-0010.

46. Şentürk, İ.; Alzein, M. Adsorption of Acid Violet 17 Onto Acid-Activated Pistachio Shell: Isotherm, Kinetic and Thermodynamic Studies. Acta Chimica Slovenica 2020, 67, 55-69, http://doi.org/10.17344/acsi.2019.5195.

47. Weber, T.W.; Chakravorti, R.K. Pore and solid diffusion models for fixed-bed adsorbers. AICHE Journal 1974, 20, 228-238, https://doi.org/10.1002/aic.690200204.

48. Desta, M.B. Batch sorption experiments: Langmuir and Freundlich isotherm studies for the adsorption of textile metal ions onto teff straw (Eragrostis tef) agricultural waste. Journal of Thermodynamics 2013, 2013, 375830, https://doi.org/10.1155/2013/375830.

49. Domingos, R.F.; Rafiei, Z.; Monteiro, C.E.; Khan, M.A.K.; Wilkinson, K.J. Agglomeration and dissolution of zinc oxide nanoparticles: role of $\mathrm{pH}$, ionic strength and fulvic acid. Environmental Chemistry 2013, 10, 306-312, http://doi.org/10.1071/EN12202.

50. Dai, H.; Sun, T.; Han, T.; Guo, Z.; Wang, X.; Chen, Y. Aggregation behavior of zinc oxide nanoparticles and their biotoxicity to Daphnia magna: Influence of humic acid and sodium alginate. Environmental Research 2020, 191, 110086, https://doi.org/10.1016/j.envres.2020.110086.

51. Gasim, M.B.; Khalid, N.A.; Muhamad, H. The influence of tidal activities on water quality of Paka River Terengganu, Malaysia. Malaysian Journal of Analytical Sciences 2015, 19, 979-990, http://www.ukm.my/mjas/v19_n5/pdf/MuhammadBarzani_19_5_9.pdf

52. Dong, Y.-n.; Li, X.; Huang, Y.; Wang, H.; Li, F. Coagulation and Dissolution of Zinc Oxide Nanoparticles in the Presence of Humic Acid Under Different pH Values. Environmental Engineering Science 2016, 33, 347-353, http://doi.org/10.1089/ees.2015.0396. 
53. Wang, X.; Sun, T.; Zhu, H.; Han, T.; Wang, J.; Dai, H. Roles of pH, cation valence, and ionic strength in the stability and aggregation behavior of zinc oxide nanoparticles. Journal of Environmental Management. 2020, 267, 110656, https://doi.org/10.1016/j.jenvman.2020.110656.

54. Singh, R.; Dutta, S. The role of $\mathrm{pH}$ and nitrate concentration in the wet chemical growth of nano-rods shaped $\mathrm{ZnO}$ photocatalyst. Nano-Structures \& Nano-Objects $\mathbf{2 0 1 9}, \quad 18, \quad 100250$, https://doi.org/10.1016/j.nanoso.2019.01.009.

55. Han, J.; Qiu, W.; Gao, W. Potential dissolution and photo-dissolution of ZnO thin films. Journal of Hazardous Materials 2010, 178, 115-122, http://doi.org/10.1016/j.jhazmat.2010.01.050.

56. Han, Y.; Kim, D.; Hwang, G.; Lee, B.; Eom, I.; Kim, P.J.; Tong, M.; Kim, H. Aggregation and dissolution of $\mathrm{ZnO}$ nanoparticles synthesized by different methods: Influence of ionic strength and humic acid. Colloids and Surfaces: Physicochemical Engineering Aspects 2014, 451, 7-15, http://doi.org/10.1016/j.colsurfa.2014.03.030.

57. Oskoei, V.; Dehghani, M.H.; Nazmara, S.; Heibati, B.; Asif, M.; Tyagi, I.; Agarwal, S.; Gupta, V.K. Removal of humic acid from aqueous solution using UV/ZnO nano-photocatalysis and adsorption. Journal of Molecular Liquids 2016, 213, 374-380, http://dx.doi.org/10.1016/j.molliq.2015.07.052.

58. Khan, R.; Inam, M.A.; Park, D.R.; Zam Zam, S.; Shin, S.; Khan, S.; Akram, M.; Yeom, I.T. Influence of Organic Ligands on the Colloidal Stability and Removal of ZnO Nanoparticles from Synthetic Waters by Coagulation. Processes 2018, 6, 170, http://dx.doi.org/10.3390/pr6090170.

59. Mekonnen, E.; Yitbarek, M.; Soreta, T.R. Kinetic and thermodynamic studies of the adsorption of Cr(VI) onto some selected local adsorbents. South African Journal of Chemistry 2015, 68, 45-52, http://doi.org/10.17159/0379-4350/2015/v68a7.

60. Odzak, N.; Kistler, D.; Sigg, L. Influence of daylight on the fate of silver and zinc oxide nanoparticles in natural aquatic environments. Environmental Pollution 2017, 226, 1-11, http://doi.org/10.1016/j.envpol.2017.04.006.

61. Li, M.; Lin, D.; Zhu, L. Effects of water chemistry on the dissolution of $\mathrm{ZnO}$ nanoparticles and their toxicity to Escherichia coli. Environmental Pollution 2013, 173, 97-102, http://doi.org/10.1016/j.envpol.2012.10.026.

62. Pansamut, G.; Charinpanitkul, T.; Suriyawong, A. Removal of humic acid by photocatalytic process: effect of light intensity. Engineering Journal 2013, 17, 25-32, http://doi.org/10.4186/ej.2013.17.3.25.

63. Goodhead, R.M.; Johnston, B.D.; Cole, P.A.; Baalousha, M.; Hodgson, D.; Iguchi, T.; Lead, J.R.; Tyler, C.R. Does natural organic matter increase the bioavailability of cerium dioxide nanoparticles to fish? Environmental Chemistry 2015, 12, 673-682, http://doi.org/10.1071/EN15003. 